\section{Schedule-induced polydipsia and aggression in rats*}

\author{
NORMAN HYMOWITZ \\ Rutgers University, New Brunswick, N.J. 08903
}

In Experiment 1, two groups of rats were exposed to an increasing series of fixed-ratio (FR) food schedules. One group had free access to water within the chamber, while the other group had free access to a target animal. The rats with water available demonstrated schedule-induced polydipsia (SIP), while the second group failed to demonstrate schedule-induced aggression (SIA). In Experiment 2, rats were exposed to random alternations between FR 200 and FR 20, with a target animal available within the operant chamber. No evidence of increases in aggression was found.

Food-deprived animals that receive food pellets on intermittent schedules often develop "schedule-induced" behaviors, i.e., postpellet activities which are not related, by actual or adventitious contingencies, to the delivery of food pellets. Examples are schedule-induced polydipsia (SIP) (Falk, 1961), wheel running (Levitsky \& Collier, 1968), air licking (Mendelson \& Chillag, 1968), and pica (Villarreal, 1967). These behaviors are acquired gradually over the course of several sessions (Hymowitz, Freed, \& Lester, 1970), are excessive in extent (Falk, 1961), and continue unabated as long as the animals are exposed to the proper experimental conditions (e.g., Hymowitz, 1971).

One type of schedule-induced behavior, schedule-induced aggression (SIA), has been interpreted as providing support for modified versions of the frustration-aggression hypothesis (Berkowitz, 1969). Berkowitz's application suggests that SIA is an elicited behavior, perhaps elicited by conditions of nonreward imposed by periods of extinction and intermittent food schedules. Since SIA has been likened to SIP in a number of ways (Flory, 1969), comparisons between the two behaviors may prove useful in understanding the basis for a variety of schedule-induced phenomena.

Despite similarities between SIP and SIA, important differences exist. Whereas SIP is acquired gradually, SIA occurs full blown as soon as the animal is exposed to the experimental treatment (Gentry, 1968). Attack behavior increases following the onset of extinction (Azrin, Hutchinson, \& Hake, 1966), may be transitory in nature (Cherek \& Pickens, 1970), and may persist long after barpressing has

* This research was supported by Fellowship MH-44801 to Norman Hymowitz and NSF Grant GB-7951 to $M$. R. D'Amato. Reprints may be obtained from Norman Hymowitz, Department of Psychology, Rutgers University, New Brunswick, N.J. 08903. extinguished (Hutchinson, Azrin, \& Hunt, 1968). SIP is nontransitory and ceases immediately when pellets are no longer delivered (Freed, Carpenter, \& Hymowitz, 1970). The purpose of the present research, then, is to compare SIA and SIP in rats under similar experimental conditions. Hopefully, these comparisons will add to our understanding of schedule-induced behaviors and the role which such behaviors play in the occurrence of aggression.

\section{EXPERIMENT 1}

Subjects and Apparatus

The experimental (E) animals were six naive Long-Evans hooded rats, three males (weighing 350-400 g) and three females (weighing 250-300 g), housed in individual home cages and maintained on Purina Laboratory Chow.

Naive Sprague-Dawley male and female albino rats, weighing from 10 to $50 \mathrm{~g}$ less than hooded rats, served as target $(\mathrm{T})$ animals. The $\mathrm{T}$ animals were housed in pairs in their home cages. Throughout the experiment, $T$ animals were repeatedly replaced. This was due either to the growth of the $\mathrm{T}$ rat or because the $T$ rat learned to eat the barpresser's food pellets.

The apparatus consisted of Grason-Stadler operant conditioning chambers and associated electromechanical programming equipment, Gerbrands cumulative recorders, and a 50-ml drinking tube located within each chamber on the wall to the right of, and adjacent to, the wall containing the rat lever. The drinking spout was located 2 in. above the grid floor and $3 \mathrm{in}$. from the food magazine. Noyes pellets $(.045 \mathrm{~g})$ served as reinforcers.

\section{Procedure}

Female $E$ rats underwent 7 days of weight reduction to $80 \%$ of their free-feeding weight; the males were reduced to $80 \%$ of their predicted weight, based on growth curves derived from rats of similar age and weight who were allowed free access to food throughout the experiment.
Two rats of the same sex, a food-satiated $T$ and an $E$ rat, were paired and placed in the Skinner box for five daily 40-min sessions prior to barpress and magazine training. Observations of the rats during each daily session served to determine baseline levels of attack frequency. When attacks were observed, the $\mathrm{E}$ pressed a switch, which in turn pulsed a response counter and the event pen on the cumulative recorder.

After completion of the five baseline sessions, and in the absence of the $T$ animals, the $E$ rats were shaped to barpress. Each $E$ rat received one session of 150 pellets on FR 1 or $1 \mathrm{~h}$ of shaping, whichever came first. One session of 100 pellets on FR 1 and five 40-min sessions on FR 15 ensued. The $T$ rats were then reintroduced, and the $\mathrm{E}$ rats were exposed to five daily 40-min sessions of FR 25, 50,75, and 100.

Attack behavior involved biting and/or striking with forepaws and was accompanied by defensive reactions (flight, submission, and counterattack) by the $T$ animal. Fighting bouts, distinguished from each other by brief pauses between aggressive thrusts, were scored when the $E$ animal physically contacted the $T$ rat.

Two other $E$ rats, a male and a female, underwent similar baseline, shaping, and experimental treatment with water, rather than a $T$ animal, freely available in the chamber. SIP was studied during each FR condition. Results

Figure 1 shows the number of attacks for each $\mathrm{E}$ animal during each experimental condition. Individual $t$ tests comparing attack frequency during each FR level to baseline levels revealed a significant increase in fighting on only one occasion, during FR 50 for SA 16 (p<.01). Frequency of attacks varied considerably from day to day, and there were no obvious consistent trends in the data.

Of the fighting observed, $81 \%$ occurred in the first third of each session. This was true for baseline as well as FR conditions. In two rats, the largest percentage of fighting occurred prior to the receipt of the first pellet of a session, while, for two other rats, the greatest percentage of fighting occurred immediately after receipt of a pellet. The number of pellets followed by fighting, however, was slight when compared to the total number of pellets received in a session.

The intensity of fighting varied from mild "boxing" to intense rapid-action clawing and biting which was often accompanied by audible squealing. In most cases, aggressive bouts terminated with the $\mathrm{T}$ animal in a submissive posture. In all cases, fighting waned and eventually ceased 


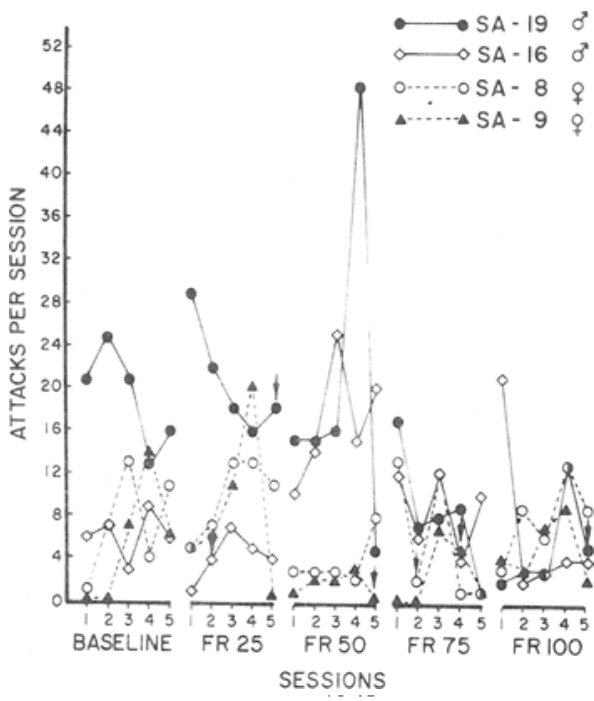

Fig. 1. Frequency of attacks during baseline and FR schedules. Arrows indicate replacement of $\mathrm{T}$ animals.

after $15 \mathrm{~min}$ of the experimental session.

Figure 2 shows the amount of water consumed during each FR condition. Because the total number of pellets received in a session differed for each FR condition, the data are presented in milliliters per pellet. Under no circumstances did the amount of water consumed in a session threaten to exceed the capacity of the $50-\mathrm{ml}$ drinking tube. In general, water consumption increased as the FR requirement increased. The failure to return to the original FR 50 drinking level probably reflects the "days effect" inherent in the data. Five days at each FR level was not enough for the postpellet drinking to stabilize. EXPERIMENT 2

Subjects and Apparatus

The same $E$ animals employed in the aggression phase of Experiment 1 were used. $T$ animals were naive albino rats. The apparatus was the same as that employed in Experiment 1.

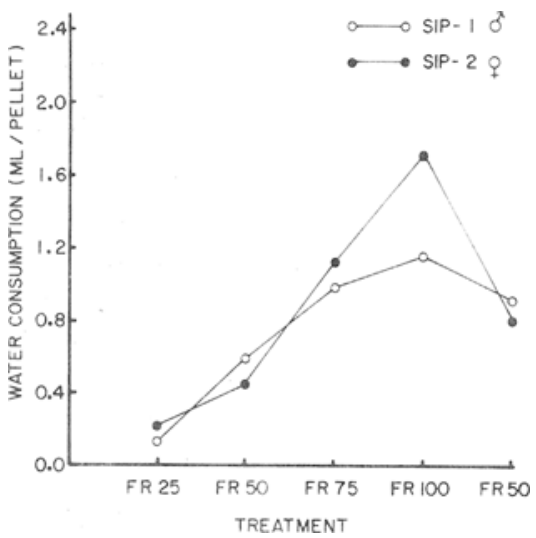

Fig. 2. Fluid consumption, in milliliters/pellet, during FR conditions.

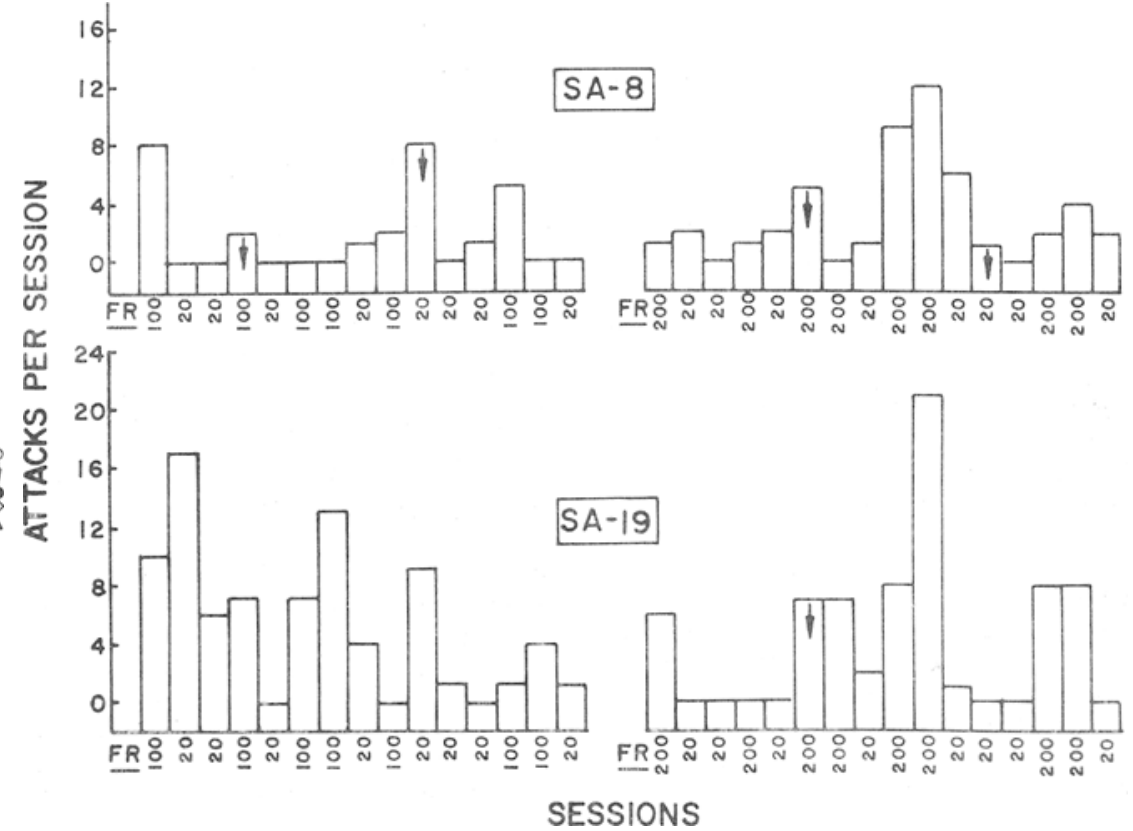

Fig. 3. Frequency of attacks during alternations between FR 20 and FR 100 and between FR 20 and FR 200. Arrows indicate replacement of $T$ animals.

Procedure

$E$ and $T$ animals were paired in the manner described previously. The $\mathrm{E}$ animals were presented with a random sequence of 16 daily $40-\mathrm{min}$ sessions on FR 100 and FR 20. Two rats, SA 16 and SA 9, were paired with the $\mathrm{T}$ rats only on FR 100 . They were alone on FR 20, so that the $\mathrm{T}$ rats served as a discriminative cue, signaling a "lean" reinforcement schedule. Sixteen more sessions of random alternations between FR 200 and

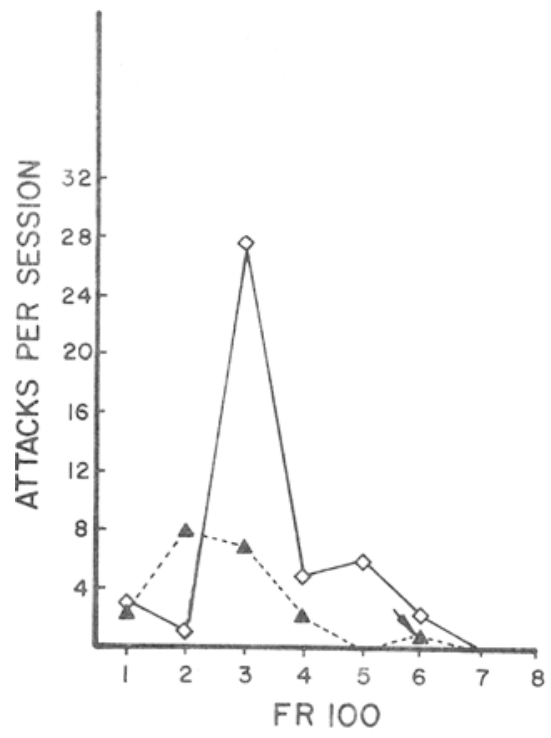

FR 20 ensued. The discriminative and nondiscriminative conditions were also employed.

Results

Figures 3 and 4 show the frequency of fighting during the FR schedules for the nondiscriminative and dis criminative conditions, respectively. Individual t tests, which compared frequency of attacks during FR 100 and FR 200 to the baseline and to the FR 100 levels reported in Experiment 1, failed to show

$$
\begin{aligned}
& \diamond \text { SA - } 16 \\
& \triangle-\cdots \text { SA- } 9
\end{aligned}
$$

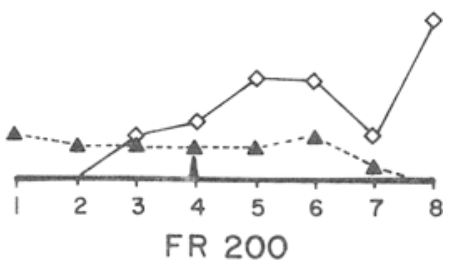

\section{SESSIONS}

Fig. 4. Frequency of attacks during FR 100 and FR 200. Arrows indicate replacement of $\mathrm{T}$ animals. 
significant increases in aggression under the conditions of Experiment 2. As in Experiment 1, 80\% of the fighting which occurred happened in the first third of the 40-min sessions. Most of the attacks occurred prior to the receipt of the first pellet. Little postpellet fighting was observed. Both animals exposed to the nondiscriminative conditions (Fig. 3 ) foright more during FR 100 and FR 200 than during FR 20. This difference was most obvious during F? 200 for SA 19, during which time virtually all fighting was confined to the FR 200 condition. Analyses of cumulative records revealed that the animals in the nondiscriminative condition emitted a burst of barpresses when they were first placed in the chamber. If they received a pellet after 20 barpresses, they continued working for food throughout the session. If no pellets were obtained following a short ratio run, the $E$ animals engaged in a considerable amount of nonbarpressing behavior throughout the session. Animals in the discriminative conditions typically displayed aggressive behavior prior to the initiation of the first ratio run.

$$
\text { DISCUSSION }
$$

Observations of pairs of rats under several conditions failed to reveal consistent postpellet attack behavior. Minimal schedule effects may have been indicated by greater fighting during FR 100 and FR 200 than during FR 20 in Experiment 2. However, fighting rarely exceeded baseline levels and did not consistently follow pellet ingestion.

SIP was demonstrated under the conditions of Experiment 1. Postpellet water consumption was related to the FR requirements and was acquired gradually over the course of several sessions. Failure to demonstrate SIA under conditions conducive to SIP places another limitation on the extent to which analogies between SIP and SIA can be extended. More direct comparison between SIP and SIA in pigeons and monkeys are in order.

SIA has been reported in rats (Gentry \& Schaeffer, 1969). It is not clear, however, if the reported aggression may be appropriately classified as SIA. The reported fighting did not occur following the receipt of food pellets nor was it related to the length of the interpellet interval (more fighting during FR 20 than during FR 40 or FR 60), two chief characteristics of SIP.

Failure to demonstrate increases in attack behavior under the conditions of the present study is consistent with previous research ( $S$ cott \& Fredericson, 1951; Seward, 1945), which suggested that conditions of frustrative nonreward did not inevitably elicit aggression in rats and a variety of other species. These findings should serve as a caution to social psychologists (e.g., Berkowitz, 1969) who interpret reports of SIA in pigeons as objective support for modified versions of the frustration-aggressions hypothesis.

\section{REFERENCES}

AZRIN, N. H., HUTCHINSON, R. R., \& HAKE, D. F. Extinction-induced aggression. Journal of the Experimental Analysis of Behavior, 1966, 9, 191-204. BERKOWITZ, L. Roots of aggression. New York: Atherton, 1969.
CHEREK, D. R., \& PICKENS, R Schedule-induced aggression as a function of fixed-ratio value. Journal of the Experimental Analysis of Behavior, 1970 , 14, 309-311.

FALK, J. L. Production of polydipsia in normal rats by an intermittent food schedule. Science, 1961, 133, 195-196.

FLORY, R. K. Attack behavior as a function of minimum interfood interval. Journal of the Experimental Analysis of Behavior, 1969, 12, 825-828.

FREED, E, X., CARPENTER, J. A., \& HYMOWITZ, N. Acquisition and extinction of schedule-induced polydipsic consumption of alcohol and water. Psychological Reports, 1970, 26. 915-922.

G E T T Y W. D. Fixed-ratio schedule-induced aggression. Journal of the Experimental Analysis of Behavior. $1968,11813-817$

GENTRY, W. D., \& SCHAEFFER, R. W The effect of $F R$ response requirement on aggressive behavior in rats. Psychonomic Science, 1969, 14, 236-238

HUTCHINSON, R. R., AZRIN, N. H., \& HUNT, G. M. Attack produced by intermittent reinforcement of a concurrent operant response. Journal of the Experimental Analysis of Behavior. $1968,11,489-495$.

HYMOWITZ, N. Effects of ratio requirements, body weight deficit, and concurrent punishment on FR-induced polydipsia. Paper read at Eastern Psychological Association. New York. April 1971.

HYMOWITZ, N., FREED, E. X.. \& LESTER, D. The independence of barpressing and schedule-induced drinking. Psychonomic Science, 1970, 20, 45-46.

LEVITSKY, D.. \& COLLIER, G. Schedule-induced wheel running. Physiology \& Behavior, 1968, 3, 571-573.

MENDELSON, J., \& CHILLAG, D. Schedule-induced air licking in rats. American Zoologist, 1968, 8, 744.

SCOTT, J. P., \& FREDERICSON, E. The causes of fighting in mice and rats. Physiological Zoology, 1951, 24. 273-309.

SEWARD, J. P. Aggressive behavior in the rat. III. The role of frustration. Joumal of Comparative Psychology, 1945, 38 225-238.

VILLARREAL, J. E. Schedule-induced pica. Paper read at Eastern Psychological Association, Boston, 1967. 